\title{
PENGARUH PEMBERIAN ISCHEMIC COMPRESSION DAN STRETCHING UNTUK MENGURANGI NYERI MYOFASCIAL TRIGGER POINT OTOTUPPER TRAPEZIUS PADA PEGAWAI KLAIM BPJS DI RUMAH SAKIT GRANDMED LUBUK PAKAM TAHUN 2020
}

\section{MIFTAHUL ZANNAH ${ }^{1}$, RIO SEPTIAN ${ }^{2}$, TIMBUL SIAHAAN ${ }^{3}$, ISIDORUS JEHAMAN ${ }^{4}$, SITI SARAH BINTANG ${ }^{5}$}

\author{
1,2,3,4,5 INSTITUT KESEHATAN MEDISTRA LUBUK PAKAM \\ JL. SUDIRMAN NO.38, KEL. LUBUK PAKAM PEKAN, KEC. LUBUK PAKAM, KAB. \\ DELI SERDANG, PROPINSI SUMATERA UTARAEmail : \\ miftahuljannah@medistra.ac.id
}

DOI : $10.35451 / j k f . v 3 i 1.492$

\begin{abstract}
A myofascial trigger point is a local pain trigger point characterized by irritation, inflammation, and swelling. The main problem is that when the emphasis is made, it creates hypersensitive to pain. Myofascial trigger point occurred by adhesions, increase by malnutrition and oxygen to ischemic. The problems are pain on muscle cervical contraction and spasm, tenderness, tightness, stiffness, decrease muscle strength. Physiotherapy modalities that can be used for myofascial trigger point are ischemic compression and stretching exercise. The study aims to determine the influence of Ischemic compression and stretching exercise in patients with the Myofascial Trigger point with the pain of the Upper Trapezius muscle Trigger Point at the Grandmed Lubuk Pakam Hospital. The research method used quasiexperiments with one group pre test and post test. Samples for this research are 20 respondents who got Ischemic compression and Stretching exercise intervention. Respondents are divided into two variables, the dependent variable got stretching and the Ischemic compression method, and the independent variable is a measure for pain in myofascial trigger point syndrome. The Result of Hypotheses tests results with the Wilcoxon signedrank test result obtained by $P$-value $\leq a(0.000<0.05)$. The mean of pain based on the Numeric rating scale before intervention (pre test) is 4,60 and after the intervention (post-test) is 2,00. According to experimental decisions, there is an influence ischemic compression and stretching exercise to decrease pain in the Myofascial trigger point of the upper trapezius muscle trigger point at the Grandmed Lubuk Pakam Hospital.
\end{abstract}

Keywords : Myofascial Trigger Point, Ischemic Compression, Stretching 


\section{PENDAHULUAN}

Berbagai macam profesi yang memanfaatkan komputer, salah satunya adalah pegawai administrasi di rumah sakit GrandMed yang bekerja 6 hari selama 9 jam sehari. Posisi duduk didepan komputer pada posisi tidak ergonomi akan berdampak negatif bagi kesehatan sehingga menyebabkan keluhan muskuloskeletal. Insiden yang paling tinggi yang menyebabkan keluhan muskuloskeletal yaitu nyeri leher, tercatat keluhan nyeri leher tersebut paling rentan terjadi pada pekerja kantor dan pengguna komputer yaitu bagian administrasi (Ravichandran, Ponni, \& Asser, 2016).

Gerakan yang dominan dilakukan antara lain fleksi-ekstensi dan lateral fleksi leher, serta protaksi dan elevasi scapula pada bahu. Gerakan pada lengan meliputi abduksi - adduksi dan fleksi - ekstensi. Pada siku pergerakannya yaitu fleksi-ekstensi sedangkan untuk gerakan tangan yaitu dorsi-palmar fleksi dan radial-ulnar deviasi (Esparza, Aladro-Gonzalvo, \& Rybarczyk, 2019).

Keluhan kesehatan yang dialami oleh para pekerja yaitu Musculoskeletal Disorder (MSDs) yang merupakan permasalahan pada otot skeletal dari keluhan yang ringan sampai keluhan yang berat. Karyawan yang menggunakan komputer mempunyai kecenderungan untuk posisi kerja yang salah memiliki resiko mengalami nyeri servikal dan bahu. Keluhan nyeri leher dapat disebabkan oleh beberapa faktor (Bahrudin, 2017). Persentase kejadian setiap tahunnya diperkirakan sebesar $16,6 \%$ populasi dewasa di dunia mengeluhkan rasa tidak nyaman pada lehernya, bahkan 0,6\% akan berlanjut menjadi nyeri leher yang berat (Widyadharma \& Purwata, 2017).

Penelitian lain dilakukan pada karyawan pengguna komputer di
Belanda dan Srilanka mengalami keluhan dominan nyeri pada bahu dan regio servikal. Hasil observasi lainnya didapatkan karyawan yang menggunakan komputer di Sudan dengan prevalensi keluhan pada leher yaitu $64 \%$ dan keluhan pada bahu $41 \%$ (Silvia, Widyahening, \& Soemarko, 2017)

Berdasarkan obervasi pada 9.482 pegawai di 12 kabupaten maupun kota di Indonesia, keluhan yang umumnya diderita berupa penyakit muskuloskeletal (16\%) kardiovaskular $(8 \%)$ gangguan syaraf $(6 \%)$ gangguan pernafasan $(3 \%)$ dan gangguan THT (1.5\%) (Jalajuwita \& Paskarini, 2015). Angka kejadian nyeri leher di Indonesia dalam 1 bulan sebesar $10 \%$ dalam satu tahun sebesar $40 \%$. Prevalensi nyeri leher pada pekerja mencapai kisaran 6$67 \%$ dan dominan dialami wanita (Sunyiwara, Putri, \& Sabita, 2019)

Posisi tubuh menggunakan komputer yang tidak ergonomis pada karyawan dengan posisi duduk yang cenderung tidak ergonomis seperti posisi cenderung menghadap kebawah karena letak komputer yang terlalu rendah sehingga posisi tubuh cenderung membungkuk dan postur seperti forward head position. Keadaan tersebut membuat tubuh dalam keadaan statis hingga menyebabkan keluhan muskuloskeletal (Nadhifah, Irianto, \& Ahsaniyah, 2019). Saat tubuh berada dalam posisi statis pada waktu yang lama, terjadi kontraksi yang kontinu pada otot, terutama pada otot punggung dan leher sehingga aliran darah menjadi terhambat dan mengakibatkan suplai oksigen untuk memecah asam laktat terhambat (Winihastuti, 2016).

Posisi tersebut terjadi secara repetitif dapat menyebabkan perobekan pada jaringan hingga terjadi penumpukan sisa metabolisme. Perlengketan jaringan terjadi akibat 
kurang nutrisi dan oksigen yang menyebabkan ischemia (Atmadja, 2016). Hal tersebut akan mengakibatkan nyeri pada otot yang berkontraksi terutama pada daerah leher menyebabkan nyeri, spasme pada otot leher yang disebut myofacial trigger point (Sunyiwara, Putri, \& Sabita, 2019).

Berbagai intervensi dapat diberikan pada penderita (Myofacial Trigger Point) salah satunya dengan memberikan intervensi Fisioterapi. PERMENKES no.65 tahun 2015 dicantumkan bahwa fisioterapi merupakan bentuk pelayanan kesehatan yang ditujukan kepada individu atau kelompok untuk mengembangkan, memelihara dan memulihkan gerak dan fungsi tubuh sepanjang daur kehidupan dengan menggunakan penanganan secara manual, peningkatan gerak, peralatan (fisik, elektropeutis, dan mekanis), pelatihan fungsi, komunikasi.

Beberapa modalitas intervensi fisioterapi dapat di berikan pada penderita Myofacial Trigger Pointotot upper trapezius dengan menggunakan modalitas ultrasound (US), dry needling, hold relax, myofacial release, Ischemic compression, stretching exercise dan lain-lain (Sunyiwara, Putri, \& Sabita, 2019). Pada kesempatan ini peneliti memilih menggunakan metode ischemic compression dan stretching exercise.

Ischemic compression technique adalah teknik manual terapi yang bekerja dengan prinsip menerapkan tekanan berkelanjutan pada trigger point dan mengurangi spasme otot.Ischemic compressiondilakukan dengan cara melakukan tekanan manual dengan ibu jari pada daerah nyeri, kemudian tekanan harus dipertahankan selama 30 detik. Ischemic compression merupakan teknik yang paling efisien untuk mengobati myofacial trigger point syndrome (Esparza, Aladro-Gonzalvo, \& Rybarczyk, 2019).

Intervensi kombinasi yang dilakukan selanjutnya stretching terapi untuk meningkatkan perpanjangan jaringan lunak dengan demikian akan meningkatkan fleksibilitas dengan cara memperpanjang struktus adaptif yang memendek dan menjadi hipomobilitas (Maruli, Sutjana, \& Indrayani, 2014).

Studi pendahuluan yang dilakukan peneliti di RS. Grandmed Lubuk Pakam peneliti menemukan masalah pada pegawai kantor bagian administrasi bahwa keluhan nyeri Otot Upper Trapezius dan nyeri punggung bawah merupakan keluhan paling banyak yang dialami pada pegawai kantor unit adminitrasi di Rs. Grandmed. Berdasarkan masalah yang yang dijumpai di RS. Grandmed pada pegawai kantor unit adminitrasi mendorong peneliti untuk melakukan penelitian "Pengaruh Pemberian Ischemic compression dan Stretching Exercise Untuk Mengurangi Nyeri Myofacial Trigger Point Otot Upper Trapezius pada pegawai klaim BPJS di Rumah Sakit GrandMed Lubuk Pakam Tahun 2020".

\section{METODE}

Penelitian ini dilakukan di Rumah Sakit Grandmed Lubuk Pakam di unit Kantor Klaim BPJSyang dilakukan mulai Februari sampai Mei tahun 2020. Jenis penelitian ini merupakan penelitian Quasi experiment dengan desain penelitian one group pre dan post test. Populasi pekerja di kantor klaim BPJS di RS Grandmed sejumlah 20 orang yang memiliki tanda dan gejala. Peneliti mengunakan teknik pengambilan sampel dengan total sampling yaitu sejumlah 20 orang pekerja Kantor dan klaim BPJS di Rumah Sakit Grandmed Lubuk Pakam. 
Penelitian ini observasi dan pengukuran dilakukan sebelum dan sesudah perlakuan untuk melihat pengaruh ischemic compression dan stretching terhadap skala nyeri pada kasus myofascial trigger point. Alat ukur intensitas nyeri yang digunakan pada penelitian ini adalah Numeric Rating Scale (NRS). Data akan diuji menggunakan paired sample t-test tetapi sebelum dilakukan uji tersebut data maka dilakukan uji normalitas. Jika data berdistribusi normal maka dilakukan uji paired sample t-test, jika data tidak berdistribusi normal maka dilakukan uji wilcoxon.

\subsection{Ischemic compression}

Ischemic compression adalah suatu teknik manual terapi yang dilakukan langsung di titik trigger point agar zat sisa iritan keluar dan vasodilatasi pembuluh darah di otot upper trapezius sehingga terjadi penyerapan zat iritan penyebab nyeri hingga menurunkan allodynia dan hiperalgesia di sistem saraf (Buana, Purnawati, Sugijanto, Satriyasa, Sandi, \& Imron, 2017). Tujuannya untuk mengurangi nyeri, meningkatkan fleksibilitas, meningkatkan range of motion dan efek relaksasi

Prosedur pelaksanaan ischemic compression dapat dimulai dengan menjelaskan prosedur dan tujuan dari intervensi Ischemic Compression. Atur posisi pasien pada posisi duduk ataupun tidur terlentang dan posisi pasien sudah nyaman. Terapis akan memposisikan daerah tubuh yang akan diterapi secara pasif fleksi, abduksi dan eksternal rotasi, sehingga menimbulkan rasa paling nyaman pada otot upper trapezius.

Terapis menerapkan teknik ini dengan menggunakan ibu jari dengan penekanan tetap berada pada ambang batas toleransi rasa sakit. Tekanan secara bertahap dilepaskan dengan teknik effleurage. Intensitas latihan dilakukakan selama 3 kali pengulangan dengan durasi 30 detik diikuti dengan masa istirahat 10 detik dan frekuensi latihan dilakukan 3 kali seminggu.

\subsection{Stretching}

Stretching merupakan teknik penguluran otot dengan teknik gerakan yang dilakukan untuk meregangkan otot dan tendon yang bertujuan untuk mengulur, melenturkan, juga menambah fleksibilitas otot yang dianggap bermasalah. Tujuannya untuk mengurangi nyeri, meningkatkan fleksibilitas, meningkatkan range of motion (ROM) dan relaksasi.

Prosedur pelaksanaan stretching yaitu dengan menjelaskan pada pasien mengenai prosedur dan tujuan dari intervensi strecthing. Posisi pasien dalam keadaan duduk atau tidur terlentang dalam keadaan nyaman. Posisi kepala dan tangan dalam posisi netral. Usahakan agar leher dibagian sekitar otot trapezius aman dan tidak tegang. Tangan fisioterapi memfiksasi dibagian otot upper trapezius pada bagian posterior superior dan kepala pasien diposisikan miring ke kanan atau ke kiri, satu tangan lagi memegang bagian bahu pasien yang berlawanan dengan kepala. Otot trapezius diulurkan dan mengarah ke hetero lateral dan berlawanan dengan fungsi otot, penguluran diulang 5 atau 6 kali dalam satu tindakan selama 5 kali pengulangan dengan durasi $8-10$ detik dan frekuensi latihan dilakukan 3 kali seminggu sampai dengan batas ketegangan otot, pasien dalam keadaan rileks.

\section{HASIL PENELITIAN}

3.1 Intensitas hasil pengukuran nyeri NRS sebelum dan sesudah diberikan intervensi ischemic compression dan stretching exercise

Berdasarkan pengumpulan data yang dilakukan di rumah sakit 
menjelaskan bahwa skala nyeri yang di rasakan responden sebelum intervensi ischemic compression dan stretching adalah skala nyeri ringan sebanyak 3 orang $(15, \%)$, skala nyeri sedang sebanyak 15 orang $(75, \%)$, dan Nyeri Berat Sebanyak 2 orang (10\%). Berdasarkan skala nyeri yang dirasakan responden sesudah dilakukan intervensi ischemic compression dan stretching yaitu skala nyeri ringan sebanyak 19 orang (95\%) dan skala nyeri sedang 1 orang (5\%) (Tabel 1 ).

Tabel 1: Intensitas nyeri sebelum dan sesudah intervensi ischemic compression dan stretching exercise.

\begin{tabular}{lcccc}
\hline Skala & \multicolumn{2}{c}{ Sebelum } & \multicolumn{2}{c}{ Sesudah } \\
\cline { 2 - 5 } & $\mathrm{n}$ & $\begin{array}{c}\mathrm{f} \\
(\%)\end{array}$ & $\mathrm{n}$ & $\begin{array}{c}\mathrm{f} \\
(\%)\end{array}$ \\
\hline $\begin{array}{l}\text { Nyeri } \\
\text { ringan }\end{array}$ & 3 & $15 \%$ & 19 & $95 \%$ \\
$\begin{array}{l}\text { Nyeri } \\
\begin{array}{l}\text { sedang } \\
\text { Nyeri } \\
\text { berat }\end{array}\end{array}$ & 15 & $75 \%$ & 1 & $5 \%$ \\
\hline
\end{tabular}

\subsection{Uji normalitas}

Setelah dilakukan proses
pengumpulan data dan analisa
univariat serta uji normalitas untuk melihat data berdistribusi normal atau tidak. Jika data berdistribusi normal maka menggunakan paired sample $t$ test namun jika data tidak berdistribusi normal maka menggunakan wilcoxon test. Berdasarkan hasil uji Shapiro-wilk bahwa data tidak berdistribusi normal. Hasil uji normalitas ditentukan dari nilai sig. < 0,05 (Tabel 2).

Tabel 2: Uji normalitas Shapiro-wilk

\begin{tabular}{cc}
\hline Shapiro-wilk & Sig \\
\hline Pre &, 262 \\
Post &, 006 \\
\hline
\end{tabular}

3.3 Pengaruh rerata nyeri sebelum dan sesudah intervensi ischemic

\section{compression dan stretching exercise.}

Hasil uji hipotesis dengan uji statistik Wilcoxon Signed Rank Test pada keluhan nyeri penderita Myofascial Trigger Point Otot Upper Trapezius pre test dan post test didapatkan $p$-value $0,000 \quad(p<0,05)$. Dari hasil uji tersebut dapat disimpulkan bahwa ada pengaruh pemberian Ischemic Compression dan Stretching terhadap pengurangan nyeri penderita myofascial trigger point otot upper trapezius pada pegawai Klaim BPJS di Rumah Sakit Grandmed Lubuk Pakam (Tabel 3).

Tabel 3: Pengaruh pemberian intervensi ischemic compression dan stretching

\begin{tabular}{cccc}
\hline Nyeri & Pre Test & $\begin{array}{l}\text { Post } \\
\text { Test }\end{array}$ & $P$-value \\
\hline Mean & 4,60 & 2,00 & 0,000
\end{tabular}

\section{PEMBAHASAN}

Hasil uji statistik menggunakan Wilcoxon Signed Rank Test dari tabel 4.3 diperoleh $p$-value a $0,000<0,05$ ) hasil ini dapat menunjukan bahwa nilai probabilitas lebih kecil dari 0,05. Pernyataan menyatakan terdapat pengaruh yang signifikan antara nyeri sebelum dan sesudah intervensi ischemic compression dan stretching pada penderita myofascial trigger point otot upper trapezius di Rumah Sakit Grandmed Lubuk Pakam Tahun 2020. Hasil pengukuran nyeri dengan skala NRS diperoleh bahwa ischemic compression dan stretching berpengaruh terhadap penurunan nyeri myofascial trigger point syndrome otot upper trapezius.

Hasil penelitian ini sejalan dengan yang dilakukan oleh (Anggraeni, 2013) dimana hasil dari penelitian tersebut menyatakan hasil bahwa ada pengaruh signifikan antara pemberian Ischemic compression terhadap penurunan nyeri 
myofascial trigger point otot upper trapezius. Pada awal pengukuran sebelum penerapan didapatkan ratarata nilai sebesar 5,09 sedangkan sesudah penerapan didapatkan ratarata nilai sebesar 1,79. Kemudian dilakukan pengujian dengan uji related t-test dengan hasil $\mathrm{P}=0,001(\mathrm{P}<$ $0,05)$ yang berarti Ho ditolak atau ada efek penerapan teknikIschemic compression dalam menurunkan nyeri pada kasus myofasial otot upper trapezius.

Penelitian yang dilakukan oleh (Buana, Purnawati, Sugijanto, Satriyasa, Sandi, \& Imron, 2017) dimana terdapat Pengaruh Kombinasi Ischemic compression dan Ultrasound Dalam Meningkatkan Kekuatan Otot Leher Akibat Myofascial SyndromePada Penjahit Pakaian di Kabupaten Gianyar. Pada awal pengukuran sebelum dilakukannya intervensi nilai rata-rata sebesar 22,36 sedangkan sesudah dilakukannya intervensi rata-rata nilai sebesar 29,27 kemudian dilakukan pengujian dengan uji paired sample ttest dengan hasil $P$-value 0,002 ( $P<$ $0,05)$ yaitu terdapat pengaruh pemberian Ischemic compression dan ultrasound dalam meningkatkan kekuatan otot leher.

Nyeri myofascial syndrome dapat menyebabkan pelepasan asetilkolin yang terfasilitasi pada pelat ujung motorik, kontraksi yang berkelanjutan oleh serat-serat otot dan iskemik lokal dengan melepaskan zat neuroaktif dan vaskular dan nyeri otot. kondisi iskemik ini dapat menurunkan sirkulasi sehingga kekurangan nutrisi dan oksigen serta penumpukan sisa metabolisme yang mengakibatkan proses radang (Sharan, 2014). peradangan dapat menimbulkan respon neuromuscular berupa ketegangan otot di area kerusakan otot sehingga timbul viscous circle. Keadaan "vicious circle" mengakibatkan iskemia lokal sebagai manifestasi dari kontraksi otot yang kuat dan mikrosirkulasi yang tidak adekuat sehingga jaringan mengalami kekurangan nutrisi dan oksigen serta menumpuknya zat sisa metabolisme. Keadaan ini merangsang nosiseptif tipe $C$ untuk melepaskan neuropeptida yaitu subtansi P. Substansi $P$ akan membebaskan prostaglandin dan diikuti dengan pembebasan bradikinin, histamin, serotonin, yang merupakan noxious atau chemical stimuli yang dapat menimbulkan nyeri leher (Makmuriyah \& Sugijanto, 2013).

Berdasarkan penelitian yang dilakukan Esparza et al (2019) tentang efek lokal Ischemic compression terhadap myofascial trigger point syndrome, dinyatakan bahwa Ischemic compression merupakan teknik yang paling efisien untuk mengatasi myofacial trigger point syndrome. Pemberian Ischemic compression dilakukan langsung pada titik trigger point agar zat sisa iritan dapat keluar dan terjadi vasodilatasi pembuluh darah pada adhesion di otot upper trapezius sehingga terjadi penyerapan zat-zat iritan penyebab nyeri yang akan menurunkan allodynia dan hiperalgesia pada sistem saraf (Buana, Purnawati, Sugijanto, Satriyasa, Sandi, \& Imron, 2017).

Penenitian ini sama halnya dengan penelitian (Maruli, Sutjana, \& Indrayani, 2014) tentang perbandingan myofascial release dengan contract relax stretching terhadap penurunan nyeri syndrome myofascial otot upper trapeziusdidapatkan hasil adanya perbedaan penurunan nyeri sebelum dan sesudah intervensi contract relax stretching pada syndrome myofascial pada otot upper trapezius dengan nilai rata-rata 3,427 kemudaian dilakukan uji paired simple t-test didapatkan hasil nilai $P$-value $0,001 \quad(P<0,05)$ yang menyatakan terdapat pengaruh sebelum dan sesudah pemberian 
intervensi terhadap myofascial syndrome pada otot upper trapezius.

Intervensi stretching memberikan efek stimulasi pada golgi tendon organ yang dapat membantu terjadinya relaksasi pada otot setelah kontraksi. Komponen stretching membuat panjang otot dapat dikembalikan dengan mengaktifasi golgi tendon organ sehingga terjadi relaksasi karena nyeri akibat spasme otot sudah berkurang.

Berdasarkan penelitian yang dilakukan oleh (Prianthara, Winaya, \& Muliarta, 2014) tentang kombinasi contract relax stretching dan infrared terhadap penurunan nyeri myofascial pain syndrome otot upper trapezius pada mahasiswa fisioterapi Fakultas Kedokteran Universitas Udayana, didapatkan perbedaan yang bermakna pada nyeri sebelum dan sesudah intervensi contract relax stretching dan infrared. Hal tersebut menunjukan bahwa intervensi ini dapat menurunkan nyeri pada myofascial pain syndrome otot upper trapezius.

Penelitian klinis yang dilakukan oleh (Ravichandran, Ponni, \& Asser, 2016), menyatakan bahwa pemberian ischemic compression selamat 30 detik sangat efektf untuk memberikan efek iskemik dan reperfusi pada jaringan hingga terjadi vasodilatasi pembuluh darah dan mengurangi taut band.

Ischemic compression bila diaplikasikan dengan benar dapat memberikan peregangan yang lebih baik pada taut band jaringan otot daripada peregangan manual. Penerapan teknik ini menggunakan tekanan yang kuat pada titik picu yang termasuk area relatif kecil dibandingkan dengan peregangan pada seluruh area otot (Buana, Purnawati, Sugijanto, Satriyasa, Sandi, \& Imron, 2017).

Jika dilihat dari penelitian sebelumnya, sejalan dengan penelitian yang dilakukan peneliti, bahwa Ischemic compression dan stretching dapat memberikan dampak signifikan kepada 20 responden yang mengeluhkan Myofascial Trigger pointotot upper trapezius, yaitu sebelum dilakukannya intervensi ini responden mengeluhkan nyeri yang beragam dari nyeri ringan, sedang hingga berat tetapi setelah dilakukan intervensi ini 6 kali selama 2 minggu responden mengaku adanya pengurangan nyeri dari sesudah diberikan nya intervensi Ischemic compression dan stretching.

\section{KESIMPULAN DAN SARAN}

Berdasarkan hasil kajian di atas, dapat disimpulkan bahwa terdapat Pengaruh Pemberian Ischemic compressiondan Stretching Terhadap Penurunan Nyeri Myofascial Trigger pointOtot Upper Trapezius pada Pegawai Klaim Bpjs Dirumhah Sakit GrandMed Lubuk Pakam. Berdasarkan hasil penelitian dan pembahasan maka dapat disimpulkan bahwa: diperoleh nilai signifikansi sebesar $P$ value 0.000 . Hasil ini menunjukkanbahwa nilai probabilitas lebih kecil dari 0,05.

Saran untuk fisioterapi lebih lanjut agar dapat mengaplikasikan intervensi stretching yang sudah diedukasikan oleh fisioterapi di rumah dan saran bagi penelitian lanjutan agar dapat dilakukan penelitian dengan intervensi ischemic compression dan stretching pada kasus nyeri myofascial trigger point terhadap kasus nyeri otot regio lainnya.

\section{DAFTAR PUSTAKA}

Anggraeni, N. C. (2013). Penerapan Myofascial Release Technique Sama Baik Dengan Ischemic Compression Technique Dalam Menurunkan Nyeri Pada Sindroma Miofasial Otot Upper Trapezius. 1-10. 
Atmadja, A. S. (2016). Syndrome Nyeri Myofascial. 43(3), 176-179.

Bahrudin, M. (2017). Patofisiologi Nyeri (Pain). 13(1), 7-13.

Buana, N. M., Purnawati, S., Sugijanto, Satriyasa, K., Sandi, N., \& Imron, M. A. (2017). Perbedaan Kombinasi Myofascial Release Technique Dengan Ultrasound Dan Kombinasi Ischemic Compression Technique Dengan Ultrasound Dalam Meningkatkan Kekuatan Otot Leher Akibat Sindroma Miofasial Pada Penjahit Pakaian Di Kabupaten Gianyar. Sport and Fitness Journal, 5 (3), 71-77.

Jalajuwita, R. N., \& Paskarini, I. (2015). HUBUNGAN POSISI KERJA DENGAN KELUHAN MUSKULOSKELETAL PADA UNIT PENGELASAN PT. $X$ BEKASI. The Indonesian Journal of Occupational Safety and Health, 4(1), 33-42.

Makmuriyah, \& Sugijanto. (2013). Iontophoresis Diclofenac Lebih Efektif Dibandingkan Ultrasound Terhadap Pengurangan Nyeri Pada Myofascial Syndrome Musculus Upper Trapezius. Jurnal Fisioterapi , 13 (1), 17-32.

Maruli, W. O., Sutjana, I. D., \& Indrayani, A. W. (2014). Perbandingan Myofascial Release Technique Dengan Contract Relax Stretching Terhadap Penurunan Nyeri Pada Sindrom Myofascial Otot Upper Trapezius.

Nadhifah, N., Irianto, \& Ahsaniyah, A. (2019). ANALYSIS RISK FACTORS FOR NECK PAIN COMPLAINTS IN PRODUCTION WORKERS AT PT MARUKI INTERNATIONAL INDONESIA. Nusantara Medical Science Journal, 1, 1-7.

PERMENKES. (2015). Peraturan Menteri Kesehatan Republik Indonesia Nomor 65 Tahun 2015 Tentang Standar Pelayanan Fisioterapi.
Prianthara, M. D., Winaya, M. N., \& Muliarta, M. (2014). Kombinasi Strain Counterstrain dan Infrared Sama Baik Dengan Kombinasi Contract Relax Stertching dan Infrared Terhadap Penurunan Nyeri Myoafacial Pain Syndrome Otot Upper Trapezius Pada Mahasiswa Fisioterapi Fakultas Kedokteran Universitas Udayana.

Ravichandran, P., Ponni, H. K., \& Asser, P. A. (2016). Effektiveness of Ischemic Compression On Trapezius Myofascial Trigger Point In Neck Pain. Int J Physiother , 3(2), 186192.

Sharan, D. (2014). Myofascial pain syndrome: Diagnosis and management. indian journal of rheumatology, 1-4.

Silvia, N., Widyahening, I. S., \& Soemarko, D. S. (2017). Efektivitas Latihan Leher dan Bahu dalam Mengurangi Nyeri Leher dan Bahu pada Pekerja Kantor dengan Komputer: Laporan Kasus Berbasis Bukti. J Indon Med Assoc , 67 (10), 592-598.

Sunyiwara, A. S., Putri, M. W., \& Sabita, R. (2019). Pengaruh Myofacial Release Kombinasi dengan Hold Relax terhadap Myofacial Pain Syndrome. Jurnal Ilmiah Kesehatan, XII (II), 582-587.

Widyadharma, I. P., \& Purwata, T. E. (2017). Nyeri Miofasial Servikal. In T. E. Purwanto, D. R. Emril, \& Yudianta, Kelompok Studi Nyeri (pp. 123-133). Medan: Pustaka Bangsa Press.

Winihastuti, H. (2016). Hubungan Faktor Risiko Ergonomi dan Keluhan Cumulative Trauma Disorders pada Dokter Gigi di PT. X Tahun 2014. Jurnal Administrasi Rumah Sakit , 3 (1), 53-65. 
